\title{
TEACHERS' SELF-EFFICACY IN HANDLING AGGRESSIVE BEHAVIOUR AMONG KINDERGARTEN CHILDREN
}

\author{
J.C. Lee, A.S. Shminan, R.U. Khan, S.P. Voon \\ Universiti Malaysia Sarawak, UNIMAS (MALAYSIA)
}

\begin{abstract}
Aggressive behaviour among kindergarten children is not something new in the world of education. Whether they like it or not, kindergarten teachers have to accept the fact that it is part of their job to face as well as to handle aggressive behaviour among children in kindergarten. Even though most of the inservice kindergarten teachers are trained, scant attention has been paid to their self-efficacy as well as its sources in terms of handling aggressive children, especially in Malaysian setting. The objective of this study was to identify the level and sources of kindergarten teachers' self-efficacy in handling aggressive behaviour among children in kindergarten. Using the simple random sampling technique, responses to sense of self-efficacy and its sources of influence when handling aggressive behaviour among children in kindergarten were sought from 768 in-service kindergarten teachers across Malaysia via e-mail. Based on the finding of this study, Emotional Self-efficacy has the highest overall mean followed by Cognitive Self-efficacy and Behavioural Self-efficacy. In terms of sources of influence on kindergarten teachers self-efficacy, Mastery Experience contributed the highest effect followed by Verbal Persuasion and considered as prominent predictors. Thus, it is suggested that in-house training for in-service kindergarten teachers explicitly address these sources of self-efficacy. With better training opportunity and continuous professional development for in-service kindergarten teachers regarding their self-efficacy (Emotional, Cognitive, and Behavioural) in handling aggressive behaviour among children in kindergarten, it will be a win-win situation for both the teachers as well as the children.
\end{abstract}

Keywords: Teachers' Self-Efficacy, Kindergarten Children, Aggressive Behaviour.

\section{INTRODUCTION}

Even though aggressive behaviour can be a normal part of children development [1], studies have shown that it is one of the behavioural problems that has been most frequently observed in kindergarten, and considered as one of the important health problems all over the world ([3],[4]). Kindergarten children behave aggressively because they could not regulate their emotions, lack of verbal and communication skills, frustration, trauma, impulsivity, poor decision making and so on. They also become more aggressive especially due to increased motor skills and feelings of autonomy [2]. Among aggressive behaviours that can lead to problems at kindergarten are kicking, hitting, destroying facilities, angry tantrums, verbal attacking, controlling others with violence, losing temper easily, extreme irritable, throwing things and challenging the teachers ([5], [6], [12], [18]). If aggressive behaviour is not handled effectively, it is likely to get worse and can be a distressing situation for both parents and teachers.

Some parents who witnessed and even realised the aggressive behaviour of their children in kindergarten may be concerned, however, they may also at the same time hope that the teachers know what to do as well as helping their children learn how to manage their aggressive behaviour. Taking charge or handling aggressive children in kindergarten is not an easy task, and can be a stressful situation for the teachers. One of the difficult issues when handling aggressive children in kindergarten is knowing how to patiently, safely, lovingly, and calmly stop them from harming other children or even themselves. It is no doubt that aggressive behaviour among kindergarten children must be stopped or controlled, but at the same time, if it is not handled effectively, most probably the blame will go to the teachers. Although there is quite a lot of literatures on how or what kindergarten teachers can do in order to handle aggressive behaviour among kindergarten children, there is still quite limited existing data regarding what kindergarten teachers actually feel an belief about their own ability when come to dealing and handling kindergarten children with aggressive behaviour. Besides that, scant attention has been paid regarding kindergarten teachers' self-efficacy in handing aggressive children in kindergarten from different countries or region around the world, especially Malaysia. Bandura ([7], [8]) proposed that selfefficacy is one's judgement of his/her capabilities to establish and execute or perform courses of action required to achieve/accomplish designated types of performances. Every individual beliefs in his/her own capacity to achieve or do something, and self-efficacy is the individual's about his/her abilities, specifically when meeting any challenges or complete any given task successfully [9]. Hence, self- 